\title{
Sulfuric acid nucleation: power dependencies, variation with relative humidity, and effect of bases
}

\author{
J. H. Zollner ${ }^{1}$, W. A. Glasoe ${ }^{1}$, B. Panta ${ }^{1}$, K. K. Carlson ${ }^{1}$, P. H. McMurry ${ }^{2}$, and D. R. Hanson ${ }^{1}$ \\ ${ }^{1}$ Department of Chemistry, Augsburg College, Minneapolis, MN 55454, USA \\ ${ }^{2}$ Department of Mechanical Engineering, University of Minnesota, Minneapolis, MN 55455, USA
}

Correspondence to: D. R. Hanson (hansondr@augsburg.edu)

Received: 16 December 2011 - Published in Atmos. Chem. Phys. Discuss.: 12 January 2012

Revised: 6 April 2012 - Accepted: 3 May 2012 - Published: 16 May 2012

\begin{abstract}
Nucleation of particles composed of sulfuric acid, water, and nitrogen base molecules was studied using a continuous flow reactor. The particles formed from these vapors were detected with an ultrafine condensation particle counter, while vapors of sulfuric acid and nitrogen bases were detected by chemical ionization mass spectrometry. Variation of particle numbers with sulfuric acid concentration yielded a power dependency on sulfuric acid of $5 \pm 1$ for relative humidities of $14-68 \%$ at $296 \mathrm{~K}$; similar experiments with varying water content yielded power dependencies on $\mathrm{H}_{2} \mathrm{O}$ of $\sim 7$. The critical cluster contains about $5 \mathrm{H}_{2} \mathrm{SO}_{4}$ molecules and a new treatment of the power dependency for $\mathrm{H}_{2} \mathrm{O}$ suggests about $12 \mathrm{H}_{2} \mathrm{O}$ molecules for these conditions. Addition of 2-to-45 pptv of ammonia or methyl amine resulted in up to millions of times more particles than in the absence of these compounds. Particle detection capabilities, sulfuric acid and nitrogen base detection, wall losses, and the extent of particle growth are discussed. Results are compared to previous laboratory nucleation studies and they are also discussed in terms of atmospheric nucleation scenarios.
\end{abstract}

\section{Introduction}

The origin and abundance of particles in the atmosphere have long been studied due to their potential impact on human health and global climate change (IPCC, 2007; Oberdorster et al., 1992; Nel, 2005). The vast array of condensable molecules in the environment, ranging from abundant species such as water vapor to trace species such as ammonia, sulfuric acid, and organic acids, complicates the study of atmospheric nucleation. Even in laboratory settings the precise role these species play in nucleation of particles has proven difficult to decipher. Consequently, research in this area is ongoing - laboratory nucleation studies involving $\mathrm{H}_{2} \mathrm{SO}_{4}$ is the subject of this paper.

Many experiments have been performed within the $\mathrm{H}_{2} \mathrm{SO}_{4}$ and $\mathrm{H}_{2} \mathrm{O}$ system where nucleation rates $J$ and their dependency on sulfuric acid concentration and relative humidity (RH) have been explored. Dependencies on reactant concentrations (which are proportional to activities for typical conditions) is important because theory shows that the molecules present in the so-called critical cluster, i.e., the direct precursor to nascent particles, can be inferred from these dependencies (Oxtoby and Kaschiev, 1994; McGraw and Wu, 2003). Ball et al. (1999) in experiments with $\mathrm{RH}=5$-to- $15 \%$ determined power dependencies for sulfuric acid of $\sim 8$ while earlier work had power dependencies of $15(\mathrm{RH}=9,14 \%$, Wyslouzil et al., 1991) and 10-to-20 (Viisanen et al., 1997, $\mathrm{RH}=38$ and $52 \%$ ). Zhang et al. (2004) report a power dependency of 8 for sulfuric acid at $5 \% \mathrm{RH}$. More recent work explored nucleation over a wide range of relative humidities. Benson et al. (2008) report sulfuric acid power dependencies between 2 and 10 with larger values occurring at lower $\mathrm{RH}$ and Young et al. (2008) report values of $4-8$ at $15 \%$ $\mathrm{RH}$ and 3 at $23 \% \mathrm{RH}$. Brus et al. (2010) report power dependencies of 4 to 8 on sulfuric acid for experiments at 10, 30 , and $50 \% \mathrm{RH}$, i.e., with larger values at higher RH. In later experiments, they report $\sim 1.5$ for comparable $\mathrm{RH}$, attributing the difference to improved particle and $\mathrm{H}_{2} \mathrm{SO}_{4}$ detection (Brus et al., 2011). A number of experiments have explored nucleation at low sulfuric acid levels, $\sim 10^{7} \mathrm{~cm}^{-3}$ vs. $10^{8}$-to- $10^{10} \mathrm{~cm}^{-3}$ in the above studies. Berndt et al. (2005, 2006) report measured nucleation rates that follow power 
dependencies of 3 to 5 at $\mathrm{RH}$ of 11 to $50 \%$ but more recently Berndt et al. (2010) and Sipila et al. (2010) report power dependencies of 1.5 to 2 on sulfuric acid over a range of $10-50 \%$ RH. However, recent results (Kirkby et al., 2011) at comparable sulfuric acid levels and similar particle counters show a power dependency of $\sim 6$.

McMurry et al. (2000), Kulmala et al. (2004), and Kuang et al. (2010), have shown that empirical nucleation theories can explain observed boundary-layer atmospheric nucleation rates, one theory with $J$ dependent on sulfuric acid with a power dependency of 1 and the other with 2 . These observations diverge from classical nucleation theory (Doyle, 1961; Reiss, 1950; Laaksonen et al., 1995; Bein and Wexler, 2007) for neat $\mathrm{H}_{2} \mathrm{SO}_{4} / \mathrm{H}_{2} \mathrm{O}$ that predicts power dependencies of 10 to- 15 at the $\left[\mathrm{H}_{2} \mathrm{SO}_{4}\right]$ found in the atmosphere. This is generally taken as evidence that the observations are dominated by nucleation processes other than the neat $\mathrm{H}_{2} \mathrm{SO}_{4} / \mathrm{H}_{2} \mathrm{O}$ system, with ammonia or amines in ternary systems as likely candidates (Weber et al., 1998). Recently, ammonia and amines have been shown to have dramatic effects on $J$ when added to $\mathrm{H}_{2} \mathrm{SO}_{4}$ and $\mathrm{H}_{2} \mathrm{O}$ vapors (Coffman and Hegg, 1995; Ball et al., 1999; Benson et al., 2009; Erupe et al., 2010; Kirkby et al., 2011). Understanding the effect of a third species requires good knowledge of the system being affected: that of nucleation with two species (i.e., neat $\mathrm{H}_{2} \mathrm{SO}_{4}-\mathrm{H}_{2} \mathrm{O}$.)

Described here are experiments on particle formation based on the Ball et al. (1999) techniques. They were conducted over a wide range of relative humidity and sulfuric acid concentration at a constant temperature. The results provide more measurements of nucleation within the $\mathrm{H}_{2} \mathrm{SO}_{4}-\mathrm{H}_{2} \mathrm{O}$ system with gas-phase analysis of potential nitrogen base contaminants. Observed particle count rates are analyzed in terms of power dependencies to obtain critical cluster compositions. Experimental issues concerning particle detection (see e.g., Sipila et al., 2010; Berndt et al., 2010) that can complicate the interpretation of flow reactor nucleation experiments are discussed. Also, ammonia and methyl amine were added to assess their relative enhancing effects on nucleation within the neat $\mathrm{H}_{2} \mathrm{SO}_{4}-\mathrm{H}_{2} \mathrm{O}$ system.

\section{Experimental}

Similarly to Ball et al., experiments were carried out in a $5 \mathrm{~cm}$ inner diameter glass flow reactor (Fig. 1 is a schematic of the reactor) with an overall length of $150 \mathrm{~cm}$. Sulfuric acid was detected with chemical ionization mass spectrometry, and particles were detected with an ultrafine condensation particle counter (UCPC). The following presents an overview of the apparatus and technique.

The top of the vertically-aligned flow reactor serves as a mixing region where gases laden with $\mathrm{H}_{2} \mathrm{SO}_{4}$ and $\mathrm{H}_{2} \mathrm{O}$ vapor mix at a temperature of $313 \mathrm{~K}$ (about $20 \mathrm{~cm}$ long and $5 \mathrm{~cm} \mathrm{ID).} \mathrm{The} \mathrm{mixing} \mathrm{region} \mathrm{is} \mathrm{capped} \mathrm{with} \mathrm{a} \mathrm{manifold}$ (Teflon) for the nitrogen carrier gas + reactant lines. A $50 \mathrm{~mm}$

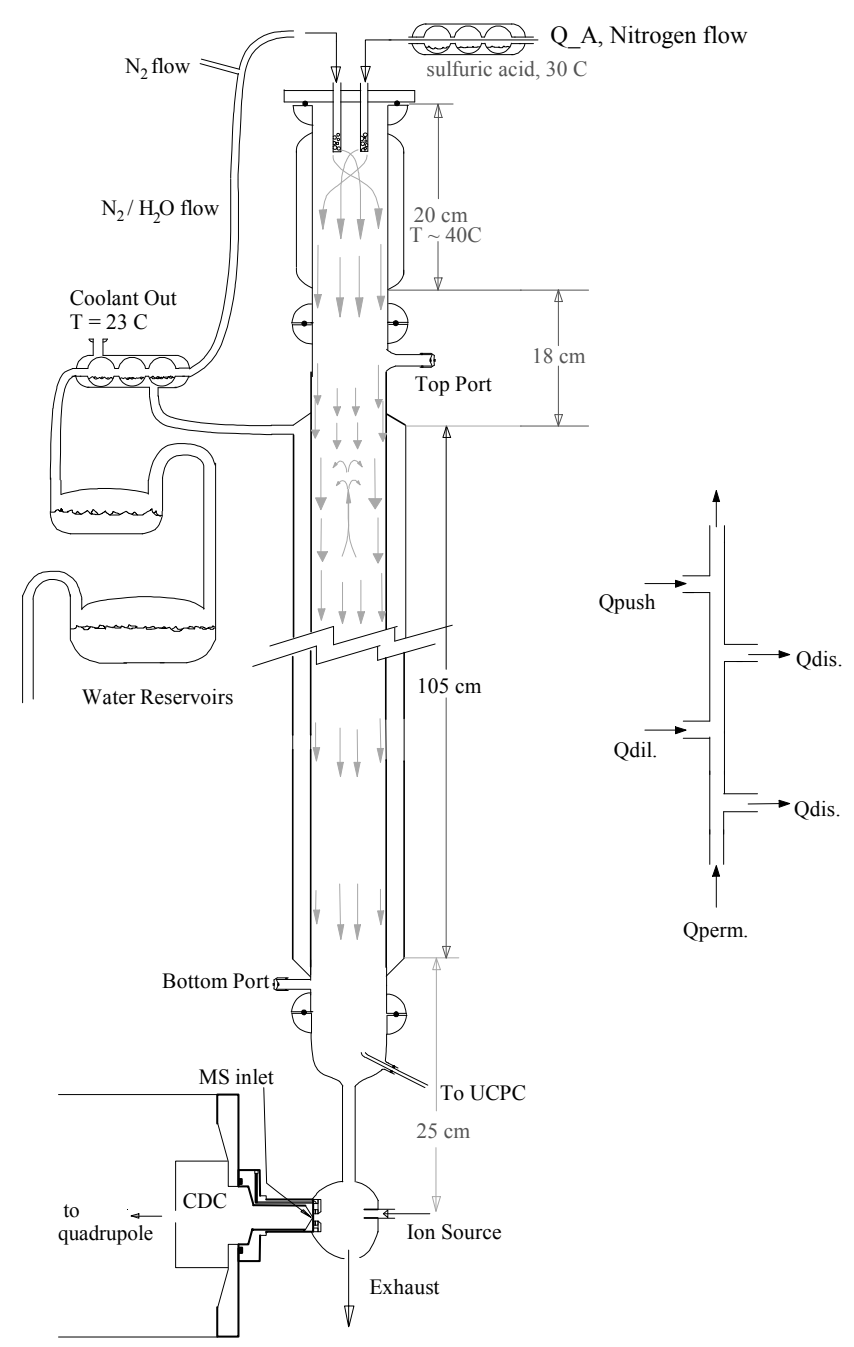

Fig. 1. Schematic drawing of the nucleation flow reactor with mixing region, transition and nucleation regions indicated. Water and $\mathrm{H}_{2} \mathrm{SO}_{4}$ sources (i.e., the reservoirs), the general flow patterns and temperatures are indicated. Top and bottom ports show where $\mathrm{N}$ bases could be added to the flow. The region of highest particle formation rates within the nucleation region are about $30 \mathrm{~cm}$ into the cooled region. The dynamic dilution system for adding $\mathrm{N}$ bases is shown to the side.

o-ring joint at the top of the mixing region seals to the manifold with a Viton o-ring encapsulated with PTFE. See the Supplement for results of tests where the mixing region temperature was varied. Following the mixing region is the nucleation region, a $\sim 120 \mathrm{~cm}$ long glass flow reactor where particle nucleation and growth occurs. A $105 \mathrm{~cm}$ length of it is surrounded by a cooling jacket maintained at $296 \mathrm{~K}$. The interface between the mixing region and the nucleation region is $\sim 18 \mathrm{~cm}$ long, is at room temperature, and the $50 \mathrm{~mm}$ o-ring joint is also sealed with a PTFE encapsulated Viton o-ring.

The total carrier $\mathrm{N}_{2}$ flow was $6 \mathrm{sLpm}\left(1 \mathrm{~min}^{-1}\right.$ at STP: $273 \mathrm{~K}, 1 \mathrm{~atm}$ ) which results in an average carrier flow speed 
of $\sim 6 \mathrm{~cm} \mathrm{~s}^{-1}$ for typical conditions of $0.98 \mathrm{~atm}$ and $296 \mathrm{~K}$. $\mathrm{N}_{2}$ was taken from a liquid nitrogen gas pack, i.e., vapor from liquid nitrogen, which is essentially free of condensable contaminants. To enhance the cleanliness of the flow reactor by minimizing its exposure to room air, a flow of nitrogen $(\sim$ $1 \mathrm{sLpm}$ ) was left on between experiments continuously now for over a year.

Water was introduced to the system by directing a portion of the carrier nitrogen over one or two water reservoirs in series at room temperature for initial humidification and then over water in a final saturator, held at the flow reactor temperature, to attain $100 \%$ humidity in this flow. The water reservoirs $(\sim 500$ and $\sim 100 \mathrm{ml})$ and saturator $(\sim 10 \mathrm{ml}$; see the left side of Fig. 1) held deionized water and a few drops to a few $\mathrm{ml}$ of $96 \%$ sulfuric acid to remove any amine or ammonia vapors that may come in with the carrier nitrogen or upon refilling with de-ionized water. A standard condition for nucleation experiments, called nucleation baseline conditions (NBC), had $27 \%$ of the total flow directed over the water. The $\mathrm{N}_{2}$ flow rate through the humidifier controlled the relative humidity of the system; this flow relative to the total flow yielded RH with NBC at $27 \%$ RH. Dew point was routinely monitored and from it the calculated $\mathrm{RH}$ agreed with the RH from the relative flows to better than $2 \%$ (Model 2000 Dewprime Dew Point Hygrometer, sampling about $2 \%$ of the flow) for RH up to $45 \%$. At higher RH the humidified flow did not achieve saturation, e.g., at flows that should give $70 \% \mathrm{RH}$, the hygrometer reading resulted in $\mathrm{RH}$ of $63-67 \%$.

Sulfuric acid was introduced by directing a portion of the carrier $\mathrm{N}_{2}$ over a $303 \mathrm{~K}$ bulk solution of sulfuric acid, consisting of about $5 \mathrm{~g}$ of $96 \% \mathrm{H}_{2} \mathrm{SO}_{4}$ held in a glass saturator ( $\sim 30 \mathrm{~cm}$ long: upper right in Fig. 1). A $\sim 15 \mathrm{~cm}$ length of $1 / 4^{\prime \prime}$ OD teflon tubing carried this flow to the mixing region: its temperature generally stabilized at $29 \pm 2{ }^{\circ} \mathrm{C}$. It was not temperature regulated and at the beginning of each run its temperature rose steadily and stabilized after an hour or two. To change the amount of sulfuric acid, the carrier flow rate that was directed to the bulk sulfuric acid was changed. This differs from the approach employed by Ball et al., where the temperature of the bulk sulfuric acid was varied while the $\mathrm{N}_{2}$ flow rate was held constant. Under NBC, the flow over bulk sulfuric acid was $1 / 6$ the total flow, or about $1 \mathrm{sLpm}$. For other $\mathrm{H}_{2} \mathrm{SO}_{4}$ contents, this flow was varied from 0.4 to $2 \mathrm{sLpm}$. The concentration of sulfuric acid exiting the flow reactor was monitored with the Ambient Pressure Mass Spectrometer (AmPMS, Hanson et al., 2011) in negative ion mode (Hanson, 2005).

Near the bottom of the reactor, about $20 \%$ of the total flow was sampled through a gently curved $30 \mathrm{~cm}$ length of $1 / 8^{\prime \prime}$ OD stainless steel, then through $\sim 50 \mathrm{~cm}$ of $1 / 4^{\prime \prime}$ OD copper tubing to an ultrafine condensation particle counter, UCPC (Stolzenberg and McMurry, 1991). The UCPC yields particle count rate data $N_{\mathrm{r}}$ (particle s ${ }^{-1}$ ) and size (using pulse height analysis) information. A multichannel analyzer (EGG optics) recorded particle counts in a set time and this was di- vided by the live time (derived in Maestro software, EGG) to yield $N_{\mathrm{r}}$ : usually live time was $99 \%$ or greater of real time except when nitrogenous bases were added. Pulse height information was recorded also however interpretation of this data is not straightforward as there are dependencies on particle composition that are difficult to quantify (Saros et al., 1996; Hanson et al., 2002; O'Dowd et al., 2004). The flow withdrawn by the UCPC was comprised of $\sim 1 \mathrm{sLpm}$ transport flow and typically $\sim 0.3 \mathrm{sLpm}$ condenser flow; the aerosol flow portion of the latter (i.e., capillary flow) was about $30 \mathrm{STP} \mathrm{cm}^{3} \mathrm{~min}^{-1}$. The condenser temperature was $8^{\circ} \mathrm{C}$ and the saturator temperature was typically $40^{\circ} \mathrm{C}$ with 1-butanol as the working fluid. Ball et al. (1999) employed the conditions outlined by Stolzenberg and McMurry (1991): $10^{\circ} \mathrm{C}$ and $37^{\circ} \mathrm{C}$ for condenser and saturator, respectively. Recently, Kuang et al. (2011) showed that the detection efficiency of this type of UCPC (butanol with a TSI 3025 or a modified 3020 TSI, Stolzenburg et al., 2011) can be greatly increased for particles in the 1.3 to $2.5 \mathrm{~nm}$ range by increasing the saturator temperature to $44^{\circ} \mathrm{C}$ and the condenser flow rate to $0.47 \mathrm{sLpm}$. The UCPC was run in this enhanced mode for a variety of conditions to investigate particle detection efficiency: the resulting $N_{\mathrm{r}}$ scaled with aerosol flow which indicates measured particle number concentration $N_{\mathrm{p}}$ was unaffected. This indicates that the particle diameter was $2 \mathrm{~nm}$ or larger.

Number density $\left(N_{\mathrm{p}}, \mathrm{cm}^{-3}\right)$ of particles was obtained by dividing $N_{\mathrm{r}}$ by the capillary flow rate, 0.5 or $0.7 \mathrm{~cm}^{3} \mathrm{~s}^{-1}$. Nucleation rate $J$ was obtained by dividing $N_{\mathrm{p}}$ by an estimated nucleation time of $8 \mathrm{~s}$, which has a high uncertainty of $+100 \%,-50 \%$ (see the Supplement).

At the end of the flow reactor, a bell-shaped converging glass joint funneled the majority of the flow into the AmPMS, configured either with negative ions to detect sulfuric acid (Hanson, 2005, primary reagent ion $\mathrm{NO}_{3}^{-} \cdot \mathrm{HNO}_{3}$ ) or with positive ions to detect ammonia and amines $\left(\mathrm{H}_{3} \mathrm{O}^{+} \cdot \mathrm{H}_{2} \mathrm{O}_{n}\right.$ reagent ions, Hanson et al., 2003, 2011)(see Supplement). About 3/4 of the total flow was directed to AmPMS. The switch between negative ions and positive ions was readily executed by reversing the polarities of the voltages. The ion source flow was humidified with a $\sim 10 \mathrm{wt} \% \mathrm{HNO}_{3}$ aqueous solution which yields ppm levels of $\mathrm{HNO}_{3}$ vapor in addition to $\mathrm{H}_{2} \mathrm{O}$ vapor. With an ion drift length of $1.7 \mathrm{~cm}$, a typical voltage drop of $0.84 \mathrm{kV}$, a typical bisulfate/nitrate ratio of $\sim 0.003$ yields a sulfuric acid concentration of about $1.1 \times 10^{9} \mathrm{~cm}^{-3}$ for NBC (Hanson, 2011, with $k t=2.6 \times$ $10^{-12} \mathrm{~cm}^{3}$ ). Note that this detected value is an average of the $\mathrm{H}_{2} \mathrm{SO}_{4}$ concentration across the ion drift region which is affected by wall losses: along the flow reactor, the funnel, and the AmPMS sampling port and drift region. For example, the detection of sulfuric acid in Ball et al. was estimated to be only about 2 -to- $14 \%$ of that present where particles were formed. Although the sampling arrangement is significantly different here, fluid dynamics simulations suggest that the current setup has a detection ratio of about $15( \pm 5) \%$, i.e., 
detected $\left[\mathrm{H}_{2} \mathrm{SO}_{4}\right] /$ peak nucleation rate $\left[\mathrm{H}_{2} \mathrm{SO}_{4}\right]$ (see Supplement, Panta et al., 2012).

To examine their effects on particle nucleation, ammonia or methyl amine was introduced to the system in a port just above the $296 \mathrm{~K}$ region ("top port"). The sources of these species were home-built permeation tubes operated at room temperature. The Teflon permeation tubes contained a small amount of liquid sample, $\sim 40 \mathrm{wt} \%$ methyl amine in water or $\sim 60 \mathrm{wt} \%$ ammonia in water (Sigma Aldrich), the tube ends were sealed by heating and inserting short lengths of glass rods. $\mathrm{N}_{2}\left(\sim 100 \mathrm{STP} \mathrm{cm}^{3} \mathrm{~min}^{-1}\right)$ was flowed over the tube, carrying the ammonia/amine that permeated the Teflon tubing to a two stage dynamic dilution system (right side of Fig. 1) before it entered the flow reactor. The permeation tubes were calibrated by titration with aqueous $\mathrm{HCl}$ by bubbling slowly $\left(\mathrm{N}_{2}\right.$ flow of $\left.\sim 20 \mathrm{STP} \mathrm{cm} \mathrm{min}^{-1}\right)$ through dilute $\mathrm{HCl}$ solutions (Carlson et al., 2012). The permeation rates were relatively large (in pmol s${ }^{-1}: 50$ for $\mathrm{NH}_{3}$ and 80 for $\mathrm{CH}_{3} \mathrm{NH}_{2}$ ) necessitating the use of a serial dynamic dilution system so that concentrations of $\sim 1$ ppmv base in the $\mathrm{N}_{2}$ flow over the perm tubes were reduced by factors of $\sim 10^{5}$ if fully mixed with no losses into the 6 sLpm flow.

A base mixing ratio of a few tens of pptv in the flow reactor could be reliably prepared which was checked with AmPMS by adding the bases to the flow through a port at the bottom of the flow reactor. AmPMS detection of ammonia or amine when it was added at the top port was much less than the amount added. Note that the background levels for the ions of interest $\left(\mathrm{NH}_{4}+\right.$ and $\mathrm{CH}_{3} \mathrm{NH}_{3}^{+}$) (Hanson et al., 2011) are substantial: for these experiments, count rates at these masses give mixing ratios of approximately $100 \mathrm{pptv}$ and 3 pptv respectively.

The zeroing mechanism for AmPMS led to severe loss of $\left[\mathrm{H}_{2} \mathrm{SO}_{4}\right]$ and thus was not used for the experiments described here. After these experiments were performed, AmPMS was attached to the flow reactor with the zeroing mechanism to better quantify N-base. No ammonia or amines were detected (see Supplement for a plot of the amines). Upper limits to the methyl and dimethyl amine mixing ratios in the effluent of the flow reactor were 0.3 and 1 pptv, respectively. Ammonia had a poor detection limit for this measurement due to a high background, 4 ppbv equivalent, and an upper limit of $170 \mathrm{pptv}$ was determined. The high background for ammonia was due to a previous exposure to outdoor air when AmPMS sampled ambient air for several weeks.

A custom-built differential mobility analyzer (geometrically equivalent to a TSI long model 3071) was used to size the particles for two sets of sulfuric acid flow rates at $68 \% \mathrm{RH}$. Due to a previous exposure, trace nitrogen bases were present in the high $\mathrm{H}_{2} \mathrm{SO}_{4}$ run while $\sim 30$ pptv $\mathrm{NH}_{3}$ was added for the low $\mathrm{H}_{2} \mathrm{SO}_{4}$ run. These bases resulted in particle numbers much higher than neat $\mathrm{H}_{2} \mathrm{SO}_{4}-\mathrm{H}_{2} \mathrm{O}$ which allowed for a size distribution measurement; neither base was detected with AmPMS (less than $0.5 \mathrm{pptv}$ ). A homemade $\sim 10 \mu \mathrm{Ci}$ particle charger was used and the charging efficiency of Fuchs (1963) was applied along with particle loss within the analyzer (Birmili et al., 1997).

Shown in Table 1 are the typical operating conditions and experimental parameters for the nucleation data presented here. Standard RH and sulfuric acid conditions were chosen (NBC) so that reproducibility and stability of the system over long periods of time could be monitored. The sulfuric acid laden flow was $1 \mathrm{sLpm}$, the humidified flow was $1.6 \mathrm{sLpm}$, and the remainder of $3.4 \mathrm{sLpm}$ was dry $\mathrm{N}_{2}$ that entered the mixing region along with the humidified flow. To achieve a range of $\mathrm{H}_{2} \mathrm{SO}_{4}$ content and $\mathrm{RH}$, flows were varied over the range of $0.4-$ to- $2 \mathrm{sLpm}, 0.8$ to $4 \mathrm{sLpm}$, and 1 to $4 \mathrm{sLpm}$, respectively, always maintaining a total of $6 \mathrm{sLpm}$. Temperatures of the mixing region $(313 \mathrm{~K})$, the nucleation region $(296 \mathrm{~K})$ and the bulk sulfuric acid $(303 \mathrm{~K})$ were held constant except for some diagnostic experiments when the temperature of the mixing region was varied to demonstrate suppression of nucleation that can occur during mixing of the reagents. The properties of the nucleation region were taken to be those of Ball et al. who determined experimentally that maximum nucleation rates occurred about $20 \mathrm{~cm}$ into the cooled nucleation region at a temperature about $2 \mathrm{~K}$ warmer than the walls. Therefore the nucleation rates reported here are for a temperature of $298( \pm 2) \mathrm{K}$. Note that RH values are reported for $296 \mathrm{~K}$ : the RH in the region for maximum nucleation are about 0.9 times the values quoted here. Discussed in the Supplement are the significant differences in the experiment from that published in Ball et al. (1999).

\section{Results}

To check for stability of the system, at the beginning of each measurement sequence and often at the end of a run, the flow of gases was set to standard conditions, NBC. Table 1 shows a summary of NBC for the entire system. Several runs with NBC as well as $27 \% \mathrm{RH}$ data at different $Q_{\mathrm{A}}$ (the nitrogen flow rate through the sulfuric acid reservoir) are compiled in Fig. 2 which plots measured $N_{\mathrm{r}}$ vs. $Q_{\mathrm{A}}$. The mass spectrometer was not operational for many of the measurements in this figure, but when concurrently running, measured $\left[\mathrm{H}_{2} \mathrm{SO}_{4}\right]$ was linearly proportional to $Q_{\mathrm{A}}$ up to $\sim 1.5 \mathrm{sLpm}$ (see Supplement). Above $1.5 \mathrm{sLpm},\left[\mathrm{H}_{2} \mathrm{SO}_{4}\right]$ does not increase in a linear fashion with $Q_{\mathrm{A}}$, due to finite rates of diffusion, etc. In Fig. 2, the particle count rate at $Q_{\mathrm{A}}=2 \mathrm{sLpm}$ falling below the typical power dependency line is due to operation in this region of $Q_{\mathrm{A}}$. The scatter in the results widens as $\left[\mathrm{H}_{2} \mathrm{SO}_{4}\right]$ decreases. The number of background particles (i.e., generated via moving parts in the gas regulator or valves or due to small leaks in the UCPC sampling line) was generally low, typically $2-10$ particles counted in $100 \mathrm{~s}$, but at times was as high as $0.5 \mathrm{~s}^{-1}$. The background particle count rate was determined about once per run by switching to $Q_{\mathrm{A}}=0$. Upon returning to $\mathrm{NBC}, N_{\mathrm{r}}$ might take an hour to return to normal 
Table 1. Nucleation Baseline Condition temperatures and flows and experimental temperatures, range of flows, and other conditions.

\begin{tabular}{lccrl}
\hline Parameter & Temp $(\mathrm{K})$ & Flow (sLpm) & Range (sLpm) & RH, P, or $\left[\mathrm{H}_{2} \mathrm{SO}_{4}\right]$ \\
\hline Dry Nitrogen & - & 3.4 & $1-4.5$ & \\
Humid Nitrogen & 296 & 1.6 & $1.2-4$ & 15 -to- $68 \% \mathrm{RH}$ \\
$Q_{\mathrm{A}}, \mathrm{H}_{2} \mathrm{SO}_{4}$ Flow & 303 & 1.0 & $0.4-2$ & $0.2-$ to- $2 \times 10^{10} \mathrm{~cm}^{-3} \mathrm{a}$ \\
Mixing Region & 313 & 6 & $4-7$ & $0.97 \mathrm{~atm}$ \\
Flow Reactor & $296^{\mathrm{b}}$ & 6 & & $\sim 1 \mathrm{in} . \mathrm{H}_{2} \mathrm{O}$ gauge \\
NBC Dew Point & 276 & - & - & $27 \% \mathrm{RH}^{\mathrm{b}}$ \\
\hline
\end{tabular}

${ }^{a}$ This is the range of $\left[\mathrm{H}_{2} \mathrm{SO}_{4}\right]$ (total: monomer + hydrates) estimated where nucleation rate peaks.

b $298 \mathrm{~K}$ where maximum nucleation occurs; RH in this region will be 0.9 times the RH values that are reported for $296 \mathrm{~K}$.

${ }^{\mathrm{c}}$ Ambient pressure was typically 0.95 -to- $0.99 \mathrm{~atm}$; pressure difference between flow reactor and ambient was $\sim 0.003 \mathrm{~atm}$.

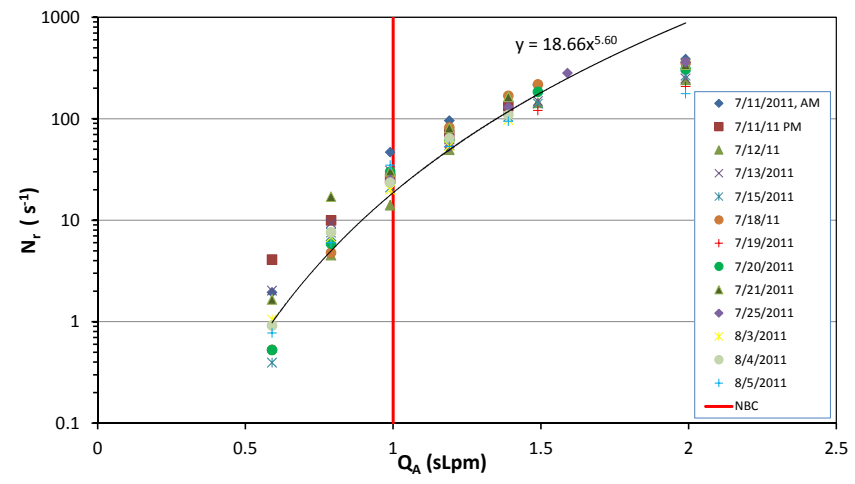

Fig. 2. Particle count rates plotted versus flow through the sulfuric acid reservoir, RH at $27 \%, T=296 \mathrm{~K}$. NBC is $Q_{\mathrm{A}}=1 \mathrm{sLpm}$ and $N_{\mathrm{r}}$ shows a variability of a factor of $\sim 2(\times 2, \div 2)$ over weeks. A typical power dependency is shown for these conditions.

levels, so that more frequent monitoring of the background particles was impractical.

The clustering of data shows the consistency of reactant and flow conditions over an extended period of time. The power dependency on $\mathrm{H}_{2} \mathrm{SO}_{4}$ remained relatively constant over that time period, averaging roughly 5.5 . For these conditions with the assumption that $\left[\mathrm{H}_{2} \mathrm{SO}_{4}\right]$ is proportional to $Q_{\text {A }}$ when it is below $1.5 \mathrm{sLpm}$, the critical cluster has $\sim 5.5$ sulfuric acid molecules. Finally, the reproducibility of NBC data was used as a monitor of the system: if particle count rates were outside the range of $20 \pm 10 \mathrm{~Hz}$ at NBC, there was some change in the system, e.g., a temperature control issue, a potential contaminant, water reservoirs need filling, leak, flow meter malfunction, UCPC needs service etc. A plot of particle count rates for NBC over a $\sim 10$ month period is displayed in the Supplement.

Shown in Fig. 3 is the particle count rate data at several $\mathrm{RH}$ vs. AmPMS ion ratio which is linearly proportional to $\left[\mathrm{H}_{2} \mathrm{SO}_{4}\right]$ at a given $\mathrm{RH}$. These data show power dependencies of 4.5 to 6 , with perhaps slightly lower values on average at the higher $\mathrm{RH}$, however not appreciably greater than the scatter. The variation of the power dependency on $\mathrm{H}_{2} \mathrm{SO}_{4}$

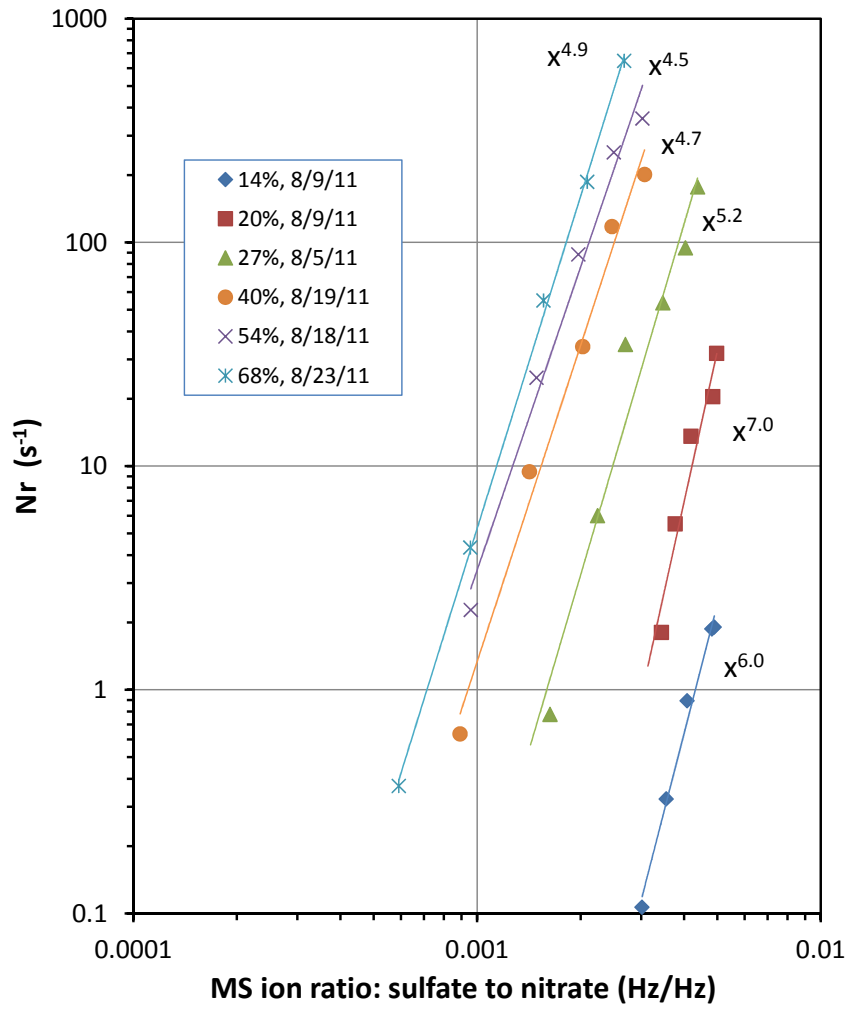

Fig. 3. Particle count rates $N_{\mathrm{r}}$ vs. ion ratio $\left(\mathrm{HSO}_{4}^{-}\right.$core ion count rate $/ \mathrm{NO}_{3}^{-}$core ion rate) observed with the mass spectrometer. The average $\mathrm{H}_{2} \mathrm{SO}_{4}$ concentration across the ion-molecule drift region, about $1.7 \mathrm{~cm}$ long, is given approximately by the ion ratio times $3.8 \times 10^{11} \mathrm{~cm}^{-3}$ while the nucleation zone peak $\mathrm{H}_{2} \mathrm{SO}_{4}$ is 5-to-10 times this. A range of RH conditions are shown here with power dependencies of 5-7.

with RH seems to be muted over this range of RH, 14-68\%. A larger set of data is presented in the Supplement.

There is a strong dependency on RH of $N_{\mathrm{r}}$ and thus the nucleation rate. As demonstrated in Fig. 3 when RH increases so does the number of particles detected by the UCPC. At $14 \% \mathrm{RH}$, there are very few particles at 0.0026 ion ratio (equivalent to $\sim 1 \times 10^{9} \mathrm{~cm}^{-3}$ ) given by the nominal flow rate 


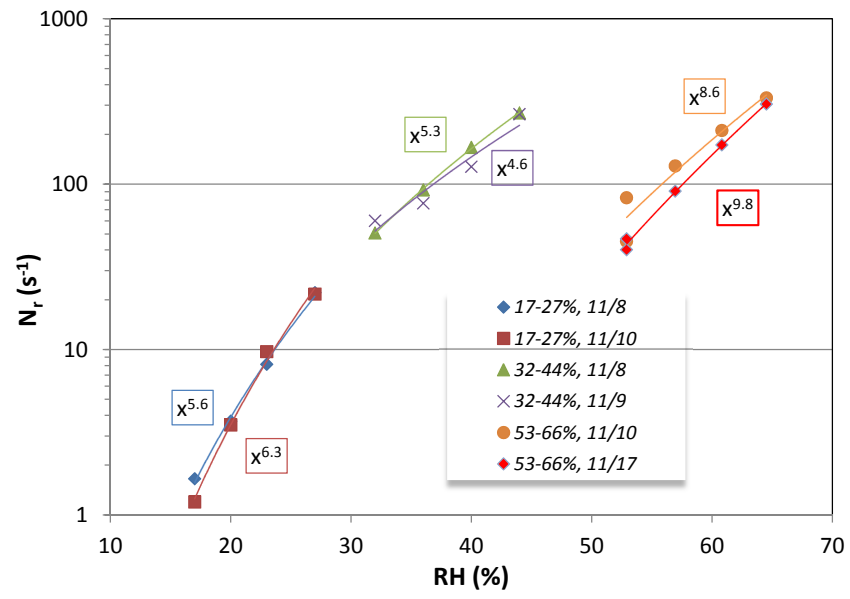

Fig. 4. Variation of $N_{\mathrm{r}}$ with $\mathrm{RH}$ at constant $\left[\mathrm{H}_{2} \mathrm{SO}_{4}\right]$ (plus hydrates). $Q_{\mathrm{A}}=1 \mathrm{sLpm}$ for the low RH (17-27\%) and medium RH (32$44 \%$ ) variations and $0.5 \mathrm{sLpm}$ for the high $\mathrm{RH}$ variation (53-66\%). The power dependencies are shown in the figure.

over the bulk sulfuric acid (1.0 sLpm). At $20 \% \mathrm{RH}$ for the same ion ratio, there is about a factor of 20 increase in $N_{\mathrm{r}}$ and at $27 \% \mathrm{RH}$ there is an additional factor of ten increase. Further increases in $\mathrm{RH}$ at the same ion ratio give a larger number of particles, e.g., at $68 \% \mathrm{RH}$, there was another factor of 50 increase in the particle count rate detected at the same sulfuric acid ion ratio.

Note that run-to-run variations in $N_{\mathrm{r}}$ of $50 \%$ for NBC were not uncommon and are believed to be due to variations in room temperature that affect which portion of the flow is sampled by the UCPC: coupled with radial gradients in particle concentrations (Ball et al., 1999) temperature dependent scatter can be introduced. Also, there were small variations in the position of the inlet. Room temperature also affects the temperature of the tubing carrying the $\mathrm{H}_{2} \mathrm{SO}_{4}$ laden flow to the mixing region. Furthermore, when $\mathrm{H}_{2} \mathrm{SO}_{4}$ vapor was monitored with the mass spectrometer and particle count rates were plotted against this measurement, scatter day-to-day was at times larger than $\pm 50 \%$. Variable temperatures could lead to variations in mixing and losses in the room temperature section and thus variations in mass spectrometer derived $\mathrm{H}_{2} \mathrm{SO}_{4}$ concentrations.

Variations of $N_{\mathrm{r}}$ with $\mathrm{RH}$ were investigated over small ranges in $\mathrm{RH}$ while maintaining a constant flow over the bulk sulfuric acid, $Q_{\mathrm{A}}$. The results are plotted in Fig. 4 and they show power dependencies on RH of 6.1 over the range 17-to$27 \% \mathrm{RH}, 5.4$ over the range 32-to- $44 \% \mathrm{RH}$, and 7.6 for 53 to-67\% RH. These were obtained by keeping $Q_{\mathrm{A}}$ constant while varying the RH with $Q_{\mathrm{A}}=1 \mathrm{sLpm}$ for the low and medium RH runs and 0.5 for the high $\mathrm{RH}$ experiment. The mass spectrometer was also sampling and measured $\mathrm{H}_{2} \mathrm{SO}_{4}$ was constant to within $5 \%$ during each run.

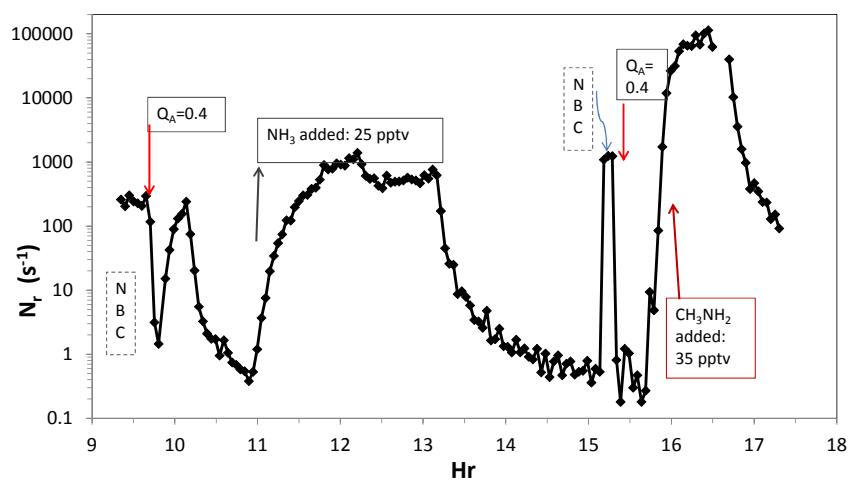

Fig. 5. $N_{\mathrm{r}}$ plotted versus time for $\mathrm{N}$ base additions to the top port. $N_{\mathrm{r}}$ is greatly affected for $Q_{\mathrm{A}}=0.4 \mathrm{sLpm}, 27 \% \mathrm{RH}$ conditions where $0.05 \mathrm{~s}^{-1}$ is typical for pristine conditions. NBC was checked twice during the experiment (09:30 and 15:15) and undetectable, residual $\mathrm{N}$ base exhibited a significant effect. AmPMS showed a detectable amount of methyl amine during its addition.

\subsection{Ammonia and amine addition}

Ammonia and methyl amine were introduced separately but in the same manner so that their relative efficacy in generating particles could be assessed. These experiments were conducted at $27 \% \mathrm{RH}$ and at a $Q_{\mathrm{A}}$ of $0.4 \mathrm{sLpm}$, which yields particle count rates of $0.05 \mathrm{~s}^{-1}$ or lower (i.e., background) in the absence of added species. Either methyl amine or ammonia were introduced to the system just below the mixing region (top port) at a rate that would give calculated mixing ratios of 2-to-50 pptv if fully mixed and absent wall losses during mixing. N-base mixing ratios quoted here are those estimated from the measured permeation rates and the known dilutions. Note that a 3-D computational fluid dynamics simulation of a similar experiment has been performed (Hanson and Eisele, 2002) and $\mathrm{NH}_{3}$ was shown to diffuse rapidly when added in this manner. An experiment is depicted in Fig. 5 where particle count rates are plotted as a function of time.

Initially, $N_{\mathrm{r}}$ for NBC was a factor of ten greater than normal, due to a previous exposure of tubing to amines. At $\sim 09: 50 \mathrm{LT}, \mathrm{NBC}$ was adjusted to very low $Q_{\mathrm{A}}, 0.4 \mathrm{sLpm}$, and $\mathrm{NH}_{3}$ was turned on and after $\sim 30 \mathrm{~min}$ it was shut off and $N_{\mathrm{r}}$ was seen to rapidly decrease below $1 \mathrm{~s}^{-1}$ which is above the $\sim 0.05 \mathrm{~s}^{-1}$ rate for the neat $27 \% \mathrm{RH}$ system: this previous exposure to ammonia, and possibly the previous day's amine experiment, had not time to flush out.

$\mathrm{NH}_{3}$ was fully introduced at around 11:00 and particle numbers increased substantially; an adjustment to the dilution system to maintain $25 \mathrm{pptv}$ is evident at 12:15. After a few hours, $N_{\mathrm{r}}$ was equal to $\sim 500 \mathrm{~s}^{-1}$. This is an enhancement of about a factor of $10^{4}$ over the neat system for these conditions. At about 13:10 the ammonia perm tube flow was diverted from the dilution system, keeping the last two stages of flow going through the dilution system and into the 
reactor, and the particle numbers can be seen to decrease at first rapidly and then gradually over the next few hours. At $15: 15$, conditions were set to $\mathrm{NBC}$ and $N_{\mathrm{r}}$ was about 50 times normal NBC, even larger than the 09:30 value; this was due to low (sub-pptv?) levels of ammonia introduced into the system with the last two stages of the dilution system.This residual ammonia or "contaminant" coming from the tubing in the dilution system was confirmed in separate experiments by shutting off all the dilution flows whereupon NBC gave normal $N_{\mathrm{r}}\left(\sim 20 \mathrm{~s}^{-1}\right)$ almost immediately. $Q_{\mathrm{A}}$ was reset to $0.4 \mathrm{sLpm}$ at 15:30.

At 15:50 methyl amine was added at about a 35 pptv level. Particle numbers increased rapidly and continued to grow such that the live time percentage of the instrument decreased below $0.05 \%$. Because the live time correction for this data is not reliable and because butanol vapor depletion within the UCPC can be significant (Saros et al., 1995) at high numbers, the $10^{5} \mathrm{~s}^{-1}$ rate indicated in the figure is a lower limit. The enhancement factor for 35 pptv methyl amine is of the order of $10^{6}$ or higher.

AmPMS monitoring of methyl amine during this time period showed an increase of about 0.4 pptv above ion background signal $(30 \mathrm{~Hz}$ signal equivalent to $3.2 \mathrm{pptv})$. Methyl amine is exposed to surfaces between the top port and the mass spectrometer and a large loss is not surprising (about a factor of 100 , i.e., $1 \%$ of the added methyl amine reached AmPMS) because surfaces have been exposed to sulfuric acid vapor and particles for thousands of hours. Note that ammonia addition did not lead to a detectable increase in AmPMS signal on a background ion count rate of about $1 \mathrm{kHz}$ (equivalent to $\sim 90 \mathrm{pptv}$.)

A second set of experiments for similar conditions were performed where ammonia was introduced at $\sim 20 \mathrm{pptv}$ and $N_{\mathrm{r}}$ was $1000 \mathrm{~s}^{-1}$, which agrees with the result above, within uncertainties. Then methyl amine was swapped in and its level was adjusted so that particle count rates matched that for 20 pptv ammonia: that was a level of about 3 pptv methyl amine. Note that once exposed to methyl amine, the dilution system required tens of hours to recover. The longer the exposure to amine, the longer the time needed to cleanse the dilution tubing system, which points to a possible mechanism: the longer the Teflon tubing is exposed to amine, the more is able to diffuse into it, to be later entrained into clean gas. A few days after this experiment, a final experiment with ammonia addition at levels of 2 and 45 pptv resulted in $N_{\mathrm{r}}$ of 40 and $7000 \mathrm{~s}^{-1}$, respectively.

Although much lower than the added ammonia, it is possible that there was enough residual methyl amine introduced to affect particle formation rates. Likewise, there was probably residual ammonia when methyl amine was sent through the dilution system. In the latter case, however, the residual ammonia probably did not significantly affect the $N_{\mathrm{r}}$ during methyl amine addition, due to methyl amine's much larger effect.
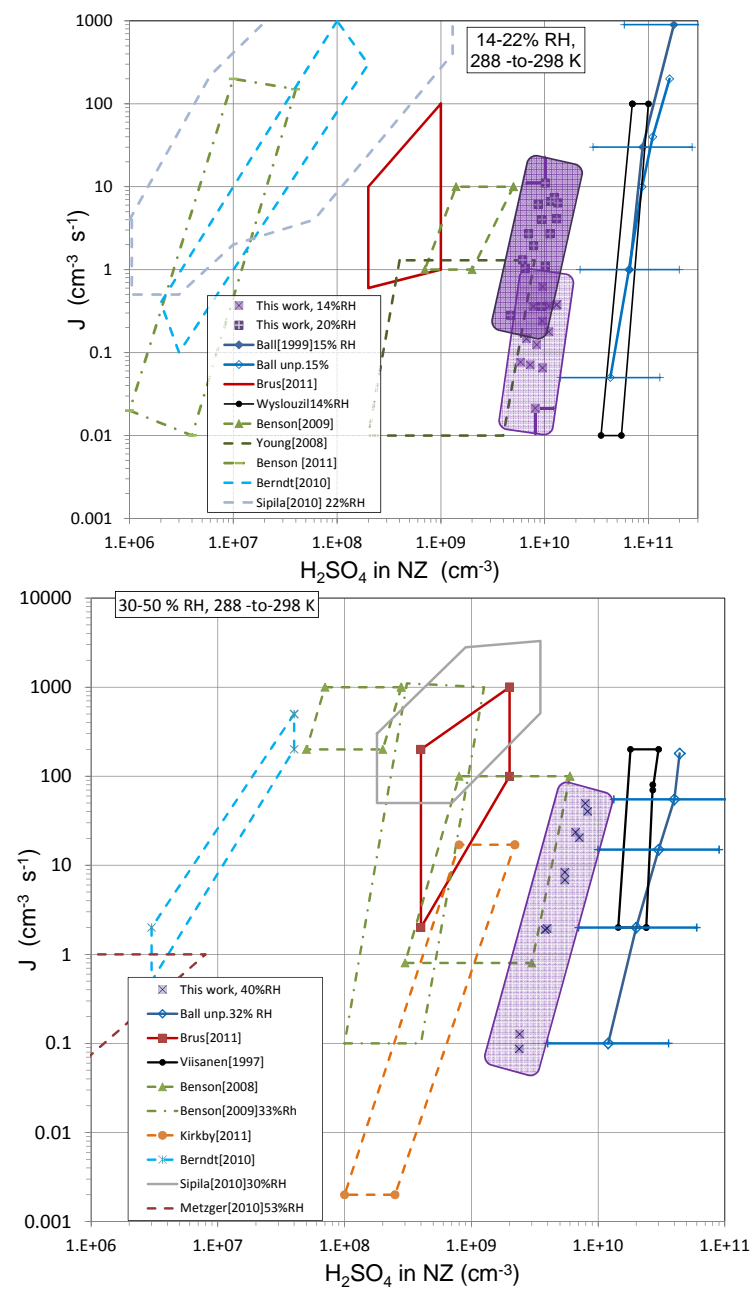

Fig. 6. Comparison of results from this work (purple + and $X$ ) to previous work at relative humidities of (a) $\sim 16 \%$ and (b) $\sim 40 \%$ where nucleation rate $J$ is plotted against $\mathrm{H}_{2} \mathrm{SO}_{4}$ concentration. Those studies with solid lines are results using $\mathrm{H}_{2} \mathrm{SO}_{4}$ vapor from sulfuric acid solutions entrained in a flow of gas (bulk) while those with dashed lines use photo-oxidation of $\mathrm{SO}_{2}$ as a source of $\mathrm{H}_{2} \mathrm{SO}_{4}$. The reported temperatures for the studies are $298 \mathrm{~K}$ except $288 \mathrm{~K}$ for Benson et al. $(2008,2009,2011)$ and Young et al. (2008); $292 \mathrm{~K}$ for Kirkby et al. (2011). Typical error bars due to uncertainties in nucleation zone concentration and residence time are shown for two points in (a). Note that $\left[\mathrm{H}_{2} \mathrm{SO}_{4}\right]$ for the Ball et al. (1999) unpublished work shown here was measured with an ion-drift arrangement similar to that used here and a factor of $10(+200 /-66 \%)$ was applied to get $\left[\mathrm{H}_{2} \mathrm{SO}_{4}\right]_{\mathrm{NZ}}$.

\subsection{Particle size}

The size distributions of particles generated in the nucleation flow reactor measured with the differential mobility analyzer indicate peaks of $\sim 7.7 \mathrm{~nm}$ diameter for $Q_{\mathrm{A}}=1.0 \mathrm{sLpm}$ and $\sim 6 \mathrm{~nm}$ for $Q_{\mathrm{A}}=0.4 \mathrm{sLpm}$. See the Supplement for size distributions. These sizes are in agreement with those reported by Ball et al. and are well above the lower limit of 
Table 2. Comparison of $\mathrm{H}_{2} \mathrm{SO}_{4}$ Power Dependencies at various $\mathrm{RH}$.

\begin{tabular}{|c|c|c|c|c|c|c|c|c|c|}
\hline RH & $\begin{array}{l}\text { This } \\
\text { work }^{\mathrm{a}}\end{array}$ & $\begin{array}{l}\text { Ball } \\
\text { et al. } \\
(1999)^{b}\end{array}$ & $\begin{array}{l}\text { Wyslouzil } \\
\text { et al. } \\
(1991)^{\mathrm{a}}\end{array}$ & $\begin{array}{l}\text { Viisanen } \\
\text { et al. } \\
(1997)^{\mathrm{a}}\end{array}$ & $\begin{array}{l}\text { Young } \\
\text { et al. } \\
(2008)^{\mathrm{c}}\end{array}$ & $\begin{array}{l}\text { Benson et al. } \\
(2006,2008 \\
2011)^{\mathrm{c}}\end{array}$ & $\begin{array}{l}\text { Berndt et al. } \\
(2005,2006 \\
2010)^{\mathrm{d}}\end{array}$ & $\begin{array}{l}\text { Brus et } \\
\text { al. }(2010 \\
2011)^{\mathrm{e}}\end{array}$ & $\begin{array}{l}\text { Kirkby } \\
\text { et al. } \\
(2011)^{f}\end{array}$ \\
\hline 14-16 & $5.5 \pm 1.5$ & $7-8$ & 16 & & $4-8$ & $2.3,4.5$ & 5 & 1.5 & \\
\hline $20-23$ & $5 \pm 2$ & - & & & 3 & 5.3 & 4,2 & - & \\
\hline $25-33$ & $6 \pm 1$ & 7 & 16 & & - & $5.6-10$ & 3 & $6,1.3$ & \\
\hline $35-44$ & $5 \pm 0.5$ & & & 20 & - & 6.3 & & - & 6 \\
\hline $45-55$ & $4 \pm 0.5$ & & & 10 & & & $3,1.9$ & 8 & \\
\hline $57-70$ & $4.2 \pm 0.6$ & & & & & & 1.9 & 1.7 & \\
\hline
\end{tabular}

${ }^{\mathrm{a}} T=298 \mathrm{~K},{ }^{\mathrm{b}} 297 \mathrm{~K}$; data at $32 \% \mathrm{RH}$ was not published, ${ }^{\mathrm{c}} 288 \mathrm{~K},{ }^{\mathrm{d}} 293 \mathrm{~K},{ }^{\mathrm{e}} 299 \mathrm{~K}$ ?, ${ }^{\mathrm{f}} 292 \mathrm{~K}$

detection for the UCPC. This is supported by the observation that changing the UCPC conditions to those of Kuang et al. (2012) made no significant difference in $N_{\mathrm{p}}$. See the Supplement for more discussion of UCPC conditions. At $\left[\mathrm{H}_{2} \mathrm{SO}_{4}\right]$ levels of $10^{10} \mathrm{~cm}^{-3}$, the rough diameter growth rate is $\sim 0.4 \mathrm{~nm} \mathrm{~s}^{-1}$ which along with a $10-20 \mathrm{~s}$ exposure time results in particle diameter increases of 4 to $8 \mathrm{~nm}$.

\section{Discussion}

\subsection{Power dependency on $\mathrm{H}_{2} \mathrm{SO}_{4}$}

The power dependency $\left(\mathrm{PD}_{1}\right)$ of the observed number of particles on sulfuric acid concentration have been reported in a number of studies and are compared in Table 2 where the $\mathrm{H}_{2} \mathrm{SO}_{4}$ power dependencies along with experimental conditions are listed. Previous work for experiments of $14 \% \mathrm{RH}$ and higher are included and results for many studies have power dependencies of 5 or above. A few recent studies report very low values of $\sim 1.5$ : the authors (Berndt et al., 2010; Sipilä et al., 2010) speculate that their particle detection efficiency was much better than all earlier work, implying a deficiency in earlier work that hid the low power dependency. However, the most recent Kirkby et al. (2011) study using identical particle instrumentation obtained $\sim 6$ for $\mathrm{PD}_{1}$, seeming to settle the debate. Furthermore, the sizes of the particles detected in this study were shown to be well above the detection threshold for the UCPC as deployed.

The power dependency reported here of 4-to-7 near $15 \% \mathrm{RH}$ is less than the 7-to-8 of Ball et al. (1999); however the small range of $\mathrm{H}_{2} \mathrm{SO}_{4}$ explored in the present work and low particle count rates limits the significance of that comparison. Previous work by Young et al. (2008) at $15 \% \mathrm{RH}$ show a $\mathrm{PD}_{1}$ of $\sim 6 \pm 2$, which is also consistent with the present and Ball et al. results. Other work by this group at 9-16\% RH (Benson et al., 2008, 2011) report lower values of $2-5$ for $\mathrm{PD}_{1}$. At $27 \% \mathrm{RH}$, however, these authors are in better agreement with the present $\mathrm{PD}_{1}$ of $6 \pm 2$ : Benson et al. $(2008,2009)$ report for $\mathrm{RH}$ of 22 -to- $30 \% \mathrm{PD}_{1}$ of 5.6to-9.5. For the range $35-44 \% \mathrm{RH}, \mathrm{PD}_{1}$ of the present work
$5 \pm 1$ agrees well with Kirkby et al. (2011) and the earlier work of Brus et al. (2010) but not the $\mathrm{PD}_{1}$ of Brus et al. (2011). Explanations for these discrepancies are based on experimental conditions or techniques, such as deficient particle counters or contaminant species.

The power dependencies on $\mathrm{H}_{2} \mathrm{SO}_{4}$ reported here vary modestly with $\mathrm{RH}$ as it increases above $14 \%$. The general trend is consistent with the Ball et al. study who found lower $\mathrm{PD}_{1}$ at higher $\mathrm{RH}$. The present results indicate that for $\left[\mathrm{H}_{2} \mathrm{SO}_{4}\right]$ of $\sim 3-10 \times 10^{9} \mathrm{~cm}^{-3}, n_{1}$ varies from $\sim 5.5$ at 20 and $27 \% \mathrm{RH}$, to 5.0 for $40 \% \mathrm{RH}$ and about 4 for 54 and $68 \%$. It appears that for the $\left[\mathrm{H}_{2} \mathrm{SO}_{4}\right]$ explored in this study, at high $\mathrm{RH}$ the number of $\mathrm{H}_{2} \mathrm{SO}_{4}$ molecules in the critical cluster $n_{1}$ is as small as 4 . This is significantly smaller than the power dependencies in the 8-to-12 range found at lower humidity (Ball et al., 1999, 2-to-10\% RH): a higher $\mathrm{PD}_{1}$ at lower RH is expected according to theory (Vehkamäki et al., 2002).

\subsection{Comparison of $\mathrm{J}$ and $\left[\mathrm{H}_{2} \mathrm{SO}_{4}\right]_{N Z}$}

Comparisons of nucleation rates $J$ as a function of $\left[\mathrm{H}_{2} \mathrm{SO}_{4}\right]_{\mathrm{NZ}}$, the $\mathrm{H}_{2} \mathrm{SO}_{4}$ concentration in the nucleation zone, i.e., where particles are formed, depend on knowledge of nucleation times and sulfuric acid losses. Generally, nucleation studies have limited accuracy for the estimates of these quantities, including the present study. Detailed knowledge of flows, temperatures, exposure times and wall losses obtained from computational fluid dynamics can be helpful (e.g., Hermann et al., 2010). The flow reactor and nucleation have been simulated using computational fluid dynamics (Panta et al., 2012). Preliminary results show (see Supplement) a factor of 7 difference between $\left[\mathrm{H}_{2} \mathrm{SO}_{4}\right]_{\mathrm{NZ}}$ and the measured $\left[\mathrm{H}_{2} \mathrm{SO}_{4}\right]$.

These estimates were applied to the particle number densities $N_{\mathrm{p}}$ and measured $\left[\mathrm{H}_{2} \mathrm{SO}_{4}\right]$ to give $J$ and $\left[\mathrm{H}_{2} \mathrm{SO}_{4}\right]_{\mathrm{NZ}}$. The $+100 /-50 \%$ uncertainty in the nucleation time dominates the additional systematic error in $J$ and the $+40 /-30 \%$ uncertainty in the factor of 7 dominates that for $\left[\mathrm{H}_{2} \mathrm{SO}_{4}\right]_{\mathrm{NZ}}$. The $J$ values are plotted vs. $\left[\mathrm{H}_{2} \mathrm{SO}_{4}\right]_{\mathrm{NZ}}$ in Fig. 6 for the (a) $14 \% \mathrm{RH}$ results and (b) for the $40 \% \mathrm{RH}$ results along with a number of previous studies. Each set of results is depicted 


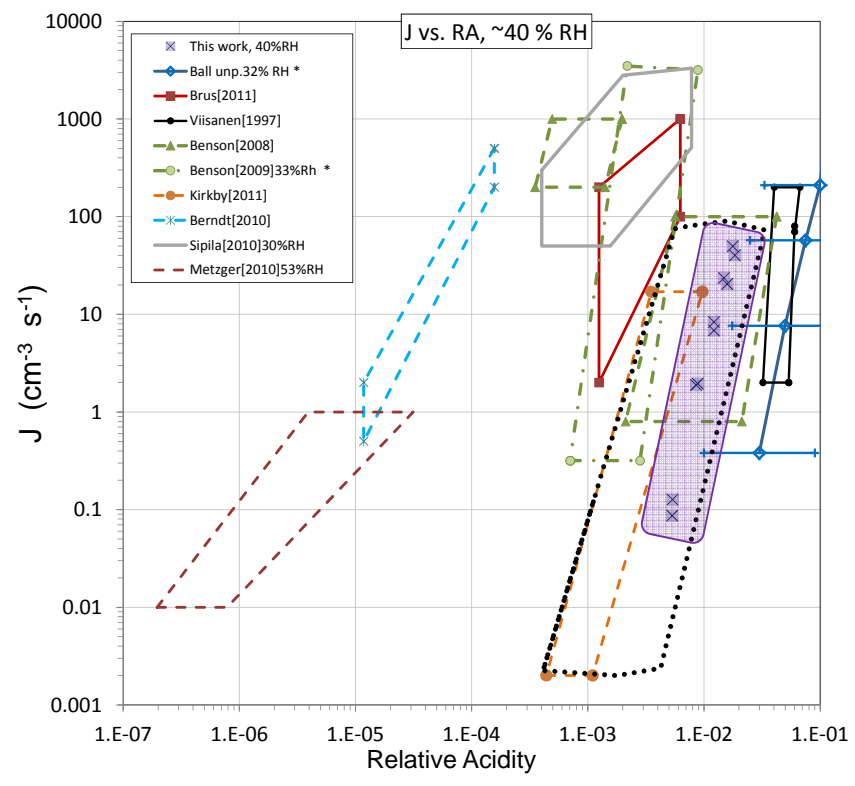

Fig. 7. As in Fig. 6 but nucleation rate $J$ is plotted against RA for $40 \% \mathrm{RH}$. For two studies (denoted with *) with results at 32 and $33 \% \mathrm{RH}$ where $\mathrm{RH}$ dependence was quoted, $J$ was corrected to $40 \% \mathrm{RH}$ equivalent using $\mathrm{PD}_{2}=6$. For three other studies conducted at RH significantly different from $40 \%$ : the Sipila et al. (2010) results for $30 \% \mathrm{RH}$ if corrected in a similar manner would cause further divergence while results for Metzger et al. (2010) (53\%) and Berndt et al. (2010) (45\%) would diverge less ( $J$ lowered by a factor of 4 and 2 respectively).

as an area on the plot that encompasses the reported uncertainties in $J$ and $\mathrm{H}_{2} \mathrm{SO}_{4}$ concentration. A few of the studies were performed at lower temperatures, which could explain some of the differences with the present results (e.g. see Fig. 7 below), but the overall wide range in nucleation rate results is not entirely due to temperature differences. Taken as a whole, it appears that using a photolytic source to oxidize $\mathrm{SO}_{2}$ could lead to nucleating species more efficient than bulk $\mathrm{H}_{2} \mathrm{SO}_{4}$. However, scatter in the data and the latest photolysis experiment at $38 \%$ RH (Kirkby et al., 2011) who report significant amounts of amines in the particles, suggest that measured $J$ s are easily skewed high possibly due to nitrogenous bases that could not be detected in the gas phase. This explanation is bolstered by our observation that a millionfold increase in $N_{\mathrm{r}}$ can be achieved with addition of methyl amine at $\sim 30$ pptv but because of loss was detected at only a 0.4 pptv level. A few studies have suggested that contaminants may have been present (Benson et al., 2011; Kirkby et al., 2011; Brus et al., 2011).

This observation along with the variety of results displayed in Fig. 6, suggests that undetected base contaminant at the pptv level could be a common problem, significantly affecting particle formation rates. For the present experiment, the level of amine needed to significantly affect the results can be estimated. Applying an extrapolation of the $N_{\mathrm{r}}$ in Ta- ble 4 using a power dependency on a base of 1.5 (see below), about $10 \mathrm{ppqv}\left(10 \mathrm{fmol} \mathrm{mol}{ }^{-1}\right)$ of methyl amine could give a particle formation rate equal to the $0.05 \mathrm{~s}^{-1}$ rate that is believed due to the neat $\mathrm{H}_{2} \mathrm{SO}_{4}-\mathrm{H}_{2} \mathrm{O}$ system. A level of $10 \mathrm{ppqv}$ is undetectable with the current instrumentation and a potential effect due to this level of base cannot be ruled out. Please see the Supplement for further discussion of this point.

\subsection{Water content of critical cluster}

The variation of $N_{\mathrm{r}}$ with $\mathrm{RH}$ yields experimental power dependencies $\mathrm{PD}_{2, \exp }$ of $J$ on $\mathrm{RH}$ of 5 to 8 ; if taken at face value, these $\mathrm{PD}_{2, \exp }$ indicate that there are 5-8 water molecules in the critical cluster. Yet the measurements do not adhere to the constrictions imposed by the nucleation theorem for binary systems (Oxtoby and Kashchiev, 1994) where the activity of the second component must be held constant while the other component's activity is varied. Here, while total $\mathrm{H}_{2} \mathrm{SO}_{4}$ was held constant as $\mathrm{RH}$ was varied over a small range, the $\mathrm{H}_{2} \mathrm{SO}_{4}$ activity was not constant due to changing hydration of $\mathrm{H}_{2} \mathrm{SO}_{4}$ molecules. Whether the bare monomer activity is the relevant parameter for nucleation calculations using the classical liquid drop model was explored by Bein and Wexler (2007). Extending those ideas leads to the following treatments for the number of water molecules $n_{2}$ in the critical cluster: (i) the observed nucleation rates as a function of RH can be corrected for changes in monomer activity, i.e., normalized, and (ii) taking advantage of the quasi-equilibrium assumption and accounting for the hydration of the main nucleating species that is on average a well-hydrated $\mathrm{H}_{2} \mathrm{SO}_{4}$ molecule.

\subsubsection{Normalized to $\mathrm{H}_{2} \mathrm{SO}_{4}$ activity}

Using the equilibrium constants for adding water molecules to sulfuric acid (Mirabel and Ponche, 1991; Noppel, 2000; Hanson and Eisele, 2000) the relative amounts of monomer $\mathrm{H}_{2} \mathrm{SO}_{4}$ at each $\mathrm{RH}$ were calculated. Then the observed rates were normalized to constant monomer $\mathrm{H}_{2} \mathrm{SO}_{4}$ activity, $a_{1}$, using the observed $\mathrm{H}_{2} \mathrm{SO}_{4}$ power dependencies, $n_{1}$, of 5.5, 5 , and 4 for the low, middle and high RH results.

$J^{\prime}=a_{1}^{-n_{1}} J$

$n_{2}=\frac{\partial \ln J^{\prime}}{\partial \ln \mathrm{RH}}=-n_{1} \cdot \frac{\partial \ln a_{1}}{\partial \ln \mathrm{RH}}+\frac{\partial \ln J}{\partial \ln \mathrm{RH}}$

where $J^{\prime}$ is the normalized rate and $J$ is the measured rate. For small changes in $\mathrm{RH}, n_{1}$ can be taken to be constant in Eq. (2). Assuming the nucleation time does not vary with $\mathrm{RH}, J$ can be replaced by particle count rates $N_{\mathrm{r}}$. A set of normalized rates $J^{\prime}$ (then renormalized to the lowest activity $J$ ) are shown in Table 3 for the different ranges of RH results and their power dependencies on RH are $\sim 12$-to- 15 . This treatment indicates there are 12-to- $15 \mathrm{H}_{2} \mathrm{O}$ molecules in the critical cluster for these conditions. 
Table 3. $\mathrm{H}_{2} \mathrm{O}$ Power Dependency Treatments due to $\mathrm{H}_{2} \mathrm{SO}_{4}$ hydration ${ }^{\mathrm{a}}$.

\begin{tabular}{cclrccc}
\hline RH & Expt'l & Monomer & Normalized $N_{\mathrm{r}}$ & Eq. (1) with $N_{\mathrm{r}}$, & Average & $n_{2}$ using \\
\hline & & fraction & $\left(\mathrm{s}^{-1}\right)$ & $n_{2}^{\text {b,d }}$ & hydrate no. & Eq. (3) ${ }^{\mathrm{c}, \mathrm{d}}$ \\
\hline $17-27$ & 6 & $0.3-0.19$ & $1.3-3 \times 10^{2}$ & 12 & 1.05 & 11.8 \\
$32-44$ & 5 & $0.15-0.095$ & $60-3 \times 10^{3}$ & 12.5 & 1.43 & 12.2 \\
$53-67$ & 9.2 & $0.07-0.045$ & $60-4 \times 10^{3}$ & 15.5 & 1.81 & 16.4 \\
\hline
\end{tabular}

${ }^{\text {a }}$ Equilibrium constants $K_{w, w-1}=\left[\mathrm{H}_{2} \mathrm{SO}_{4} \cdot\left(\mathrm{H}_{2} \mathrm{O}\right)_{w}\right] /\left[\mathrm{H}_{2} \mathrm{SO}_{4} \cdot\left(\mathrm{H}_{2} \mathrm{O}\right)_{w-1}\right] \mathrm{RH}$ with $\mathrm{RH}$ in $\% .1 / K_{w, w-1}=10,50,166,200$,

$300 \%$ for the 1 st through 5 th hydrates.

${ }^{\mathrm{b}} \mathrm{PD}_{2}$ of normalized $N_{\mathrm{r}}$ : method (i) in text.

c Expt'l PD added to hydrate no. times 5.5, 5 and 4, respectively: method (ii), Eq. (3), in text.

$\mathrm{d}$ Propagation of random errors leads to \pm 1 -to- 1.5 precision uncertainty in $n_{2}$.

\subsection{2 $\mathrm{H}_{2} \mathrm{O}$ with the $\mathrm{H}_{2} \mathrm{SO}_{4}$ hydrates}

An alternative line of reasoning takes into account the number of water molecules on average that arrive with each $\mathrm{H}_{2} \mathrm{SO}_{4}$ molecule that are in the critical cluster. It is assumed that the $\mathrm{PD}_{2, \exp }$ on $\mathrm{RH}$ of the observed rate $J$ is the extra waters beyond the average number carried in with each monomer. Then the number of waters in the critical cluster, $n_{2}$ is given by

$n_{2}=\mathrm{PD}_{2, \exp }+n_{1} \cdot$ (average hydration number of $\mathrm{H}_{2} \mathrm{SO}_{4}$ )

With the equilibrium constants for monomer hydration (equilibrium constants in 1/\% RH are given in Table 3), the average number of hydrate water molecules on an $\mathrm{H}_{2} \mathrm{SO}_{4}$ are $1.05 \pm 0.14,1.43 \pm 0.11$, and $1.81 \pm 0.11$ for the low, middle and upper RH ranges, respectively. Multiplying these by the $\mathrm{H}_{2} \mathrm{SO}_{4}$ power dependencies $n_{1}$ and adding to the $\mathrm{H}_{2} \mathrm{O}$ power dependency for total $\mathrm{H}_{2} \mathrm{SO}_{4}$ constant (the experimental column), yields the values in the last column. The result is that about 12-16 water molecules are present in the critical cluster. The agreement between these two methods is not purely coincidental as they are essentially the same mathematically: the average hydration number is closely related to the variation of $a_{1}$ with RH.

\section{4 $J$ versus Relative Acidity for $40 \%$ RH}

To take into account temperature differences, the data shown in Fig. $6 \mathrm{~b}$ is plotted vs. relative acidity (RA, the partial pressure of $\mathrm{H}_{2} \mathrm{SO}_{4}$ divided by the saturation partial pressure Ayers et al. (1980)) in Fig. 7. When plotted in this way, there is better agreement amongst the published data with a few exceptions: Metzger et al. (2010), Berndt et al. (2010), Sipila et al. (2010), and the Fig. 1a data of Benson et al. (2008) (the Fig. 1b data of this reference agrees well.) Note that an $\mathrm{PD}_{2, \exp }=6$ was applied to the $33 \%$ RH Benson et al. (2009) data and to the $32 \%$ RH unpublished Ball et al. data. Most of the data in Fig. 7 cluster around the present data and that of Kirkby et al. (2011).
Table 4. Ammonia and amine addition experiments at $27 \% \mathrm{RH}$.

\begin{tabular}{lcccc}
\hline $\mathrm{N}$ base & Level, pptv & $N_{\mathrm{r}}\left(\mathrm{s}^{-1}\right)$ & $J\left(\mathrm{~cm}^{-3} \mathrm{~s}^{-1}\right)^{\mathrm{a}}$ & $\mathrm{EF}$ \\
\hline- & 0 & $<0.05$ & $<0.01$ & - \\
$\mathrm{CH}_{3} \mathrm{NH}_{2}$ & 3 & 1000 & 125 & $2 \times 10^{4}$ \\
$\mathrm{CH}_{3} \mathrm{NH}_{2}$ & 35 & $>10^{5}$ & $>10^{4}$ & $>2 \times 10^{6}$ \\
$\mathrm{NH}_{3}$ & 2 & 40 & 5 & 800 \\
$\mathrm{NH}_{3}$ & 20 & 1000 & 125 & $2 \times 10^{4}$ \\
$\mathrm{NH}_{3}$ & 45 & 7000 & 875 & $1.4 \times 10^{5}$ \\
\hline
\end{tabular}

a $J=N_{\mathrm{r}}$ divided by aerosol sampling rate of $0.7 \mathrm{~cm}^{3} \mathrm{~s}^{-1}$ divided by $\sim 8 \mathrm{~s}$ nucleation time. ${ }^{\mathrm{b}}$ Enhancement factor over neat $\mathrm{H}_{2} \mathrm{SO}_{4}-\mathrm{H}_{2} \mathrm{O}$ system for $Q_{\mathrm{A}}=0.4 \mathrm{sLpm}$ where $\left[\mathrm{H}_{2} \mathrm{SO}_{4}\right]$ at the peak of nucleation is $\sim 3 \times 10^{9} \mathrm{~cm}^{-3}$.

A relative acidity of $4-$ to- $8 \times 10^{-3}$ gives a nucleation rate of $1 \mathrm{~cm}^{-3} \mathrm{~s}^{-1}$ at $40 \% \mathrm{RH}$. Assuming the $J$ vs. RA relationship does not vary with temperature, this RA is achieved at $252 \mathrm{~K}$ for an atmospheric $\left[\mathrm{H}_{2} \mathrm{SO}_{4}\right]=10^{7} \mathrm{~cm}^{-3}$. These temperatures are not present for most boundary layer nucleation studies (McMurry et al. (2000)), and the present measurements indicate that binary nucleation is not a likely contributor to new particle formation events in this region of the atmosphere. As suggested by Weber et al. (1999), however, $\left[\mathrm{H}_{2} \mathrm{SO}_{4}\right]$ and temperatures near the outflow of clouds can lead to RA up to 0.01 , indicating that binary nucleation can play a role in nucleation in the middle to lower troposphere.

\section{Ammonia and amines}

Table 4 contains the particle count rates for the ammonia and methyl amine addition experiments. These were taken for the following experimental conditions: $27 \% \mathrm{RH}$ and $\left[\mathrm{H}_{2} \mathrm{SO}_{4}\right]$ in the nucleation zone of $\sim 3 \times 10^{9} \mathrm{~cm}^{-3}$ where in the absence of base, particle count rates are $0.05 \mathrm{~s}^{-1}$ or less. Methyl amine is roughly 25 to 100 times more effective than ammonia when added at similar levels. This experiment result is in agreement with earlier work (Kurten et al., 2008; Berndt et al., 2010; Erupe et al., 2011) that amines are effective in promoting nucleation involving sulfuric acid.

The data in Table 4 are consistent with power dependencies of particle count rates on methyl amine of about 2 and 
on ammonia of about 1.5. More experiments are planned investigating the effects of bases on nucleation including dependencies on [base], $\left[\mathrm{H}_{2} \mathrm{SO}_{4}\right]$, and $\mathrm{RH}$. Also, the amounts of residual amines in the dilution system and their affect on particle formation rates will be explored.

Atmospheric levels of methyl amine are $<1 \%$ of ammonia throughout much of the atmosphere (Ge et al., 2011; Hanson et al., 2011) and the data in the table suggests that ammonia need only be about $30 \mathrm{pptv}$ to have the same effect as a typical atmospheric level of 3 pptv for methyl amine. These addition experiments were carried out with $\left[\mathrm{H}_{2} \mathrm{SO}_{4}\right]_{\mathrm{NZ}}$ estimated to be about $3 \times 10^{9} \mathrm{~cm}^{-3}$. This is much higher than is found in the atmosphere: daytime atmospheric levels are only about $1 / 100$ of this value (McMurry et al., 2000). Although more experimental data are required before these measurements can be applied to atmospheric conditions, the data suggests that with ammonia levels about 1000 times methyl amine levels (Nowak et al., 2005; Hanson et al., 2011), ammonia may play a larger role than does methyl amine. Yet there are a large number of amines in the atmosphere of greater abundance than methyl amine (Ge et al., 2011; Hanson et al., 2011); more data on the effects of these amines on nucleation are needed.

\section{Supplementary material related to this article is available online at: http://www.atmos-chem-phys.net/12/ 4399/2012/acp-12-4399-2012-supplement.pdf.}

Acknowledgements. This work was supported by NSF Grants 0943721, 1068201, and 1051396. Augsburg College's URGO program is acknowledged for funding travel and summer support. Correspondence with S. Clegg, A. Wexler, and E. Bien on $\mathrm{H}_{2} \mathrm{SO}_{4}$ activity and $\mathrm{S}$. Clegg regarding methyl amine in E-AIM model is gratefully acknowledged.

Edited by: K. Lehtinen

\section{References}

Ayers, G. P., Gillet, R. W., and Gras, J. L.: On the vapor pressure of sulfuric acid, Geophys. Res. Lett., 7, 433-436, 1980.

Ball, S. M., Hanson, D. R., Eisele, F. L., and McMurry, P. H.: Laboratory studies of particle nucleation: Initial results for $\mathrm{H}_{2} \mathrm{SO}_{4}$, $\mathrm{H}_{2} \mathrm{O}$, and $\mathrm{NH}_{3}$ vapors, J. Geophys. Res., 104, 23709-23718, 1999.

Bein, K. J. and Wexler, A. S.: Interpreting activity in $\mathrm{H}_{2} \mathrm{O}-$ $\mathrm{H}_{2} \mathrm{SO}_{4}$ binary nucleation, J. Chem. Phys., 127, 124316, doi:10.1063/1.2768925, 2007.

Benson, D. R., Erupe, M. E., and Lee, S. H.: Laboratorymeasured $\mathrm{H}_{2} \mathrm{SO}_{4}-\mathrm{H}_{2} \mathrm{O}-\mathrm{NH}_{3}$ ternary homogeneous nucleation rates: Initial observations, Geophys. Res. Lett., 36, L15818, doi:10.1029/2009g1038728, 2009.
Benson, D. R., Young, L. H., Kameel, F. R., and Lee, S.-H.: Laboratory-measured nucleation rates of sulfuric acid and water binary homogeneous nucleation from the $\mathrm{SO}_{2}+\mathrm{OH}$ reaction, Geophys. Res. Lett., 35, L11801, doi:10.1029/2008GL033387, 2008.

Benson, D. R., Yu, J. H., Markovich, A., and Lee, S.-H.: Ternary homogeneous nucleation of $\mathrm{H}_{2} \mathrm{SO}_{4}, \mathrm{NH}_{3}$, and $\mathrm{H}_{2} \mathrm{O}$ under conditions relevant to the lower troposphere, Atmos. Chem. Phys., 11, 4755-4766, doi:10.5194/acp-11-4755-2011, 2011.

Berndt, T., Böge, O., Stratmann, F., Heintzenberg, J., and Kulmala, M.: Rapid formation of sulfuric acid particles at nearatmospheric conditions, Science, 307, 698-700, 2005.

Berndt, T., Boge, O., and Stratmann, F.: Formation of atmospheric $\mathrm{H}_{2} \mathrm{SO}_{4} / \mathrm{H}_{2} \mathrm{O}$ particles in the absence of organics: A laboratory study, Geophys. Res. Lett., 33, L15817, doi:10.1029/2006GL026660, 2006.

Berndt, T., Stratmann, F., Sipilä, M., Vanhanen, J., Petäjä, T., Mikkilä, J., Grüner, A., Spindler, G., Lee Mauldin III, R., Curtius, J., Kulmala, M., and Heintzenberg, J.: Laboratory study on new particle formation from the reaction $\mathrm{OH}+\mathrm{SO}_{2}$ : influence of experimental conditions, $\mathrm{H}_{2} \mathrm{O}$ vapour, $\mathrm{NH}_{3}$ and the amine tert-butylamine on the overall process, Atmos. Chem. Phys., 10, 7101-7116, doi:10.5194/acp-10-7101-2010, 2010.

Birmili, W., Stratmann, F., Wiedensohler, A., Covert, D., Russell, L. M., and Berg, O.: Determination of Differential Mobility Analyzer Transfer Functions Using Identical Instruments in Series, Aerosol Sci. Technol., 27, 215-223, 1997.

Brus, D., Hyvärinen, A.-P., Viisanen, Y., Kulmala, M., and Lihavainen, H.: Homogeneous nucleation of sulfuric acid and water mixture: experimental setup and first results, Atmos. Chem. Phys., 10, 2631-2641, doi:10.5194/acp-10-2631-2010, 2010.

Brus, D., Neitola, K., Hyvärinen, A.-P., Petäjä, T., Vanhanen, J., Sipilä, M., Paasonen, P., Kulmala, M., and Lihavainen, H.: Homogenous nucleation of sulfuric acid and water at close to atmospherically relevant conditions, Atmos. Chem. Phys., 11, 5277 5287, doi:10.5194/acp-11-5277-2011, 2011.

Carlson, K. K., Panta, B., Glasoe, W. A., and Hanson, D. R.: Ammonia and Amine Permeation Tubes: Quantification, Use in AmPMS Calibrations and in Nucleation Experiments, in preparation, 2012.

Coffman, D. J. and Hegg, D. A.: A preliminary study of the effect of ammonia on particle nucleation in the MBL, J. Geophys. Res., 100, 7147-7160, 1995.

Doyle, G. J.: Self-Nucleation in the Sulfuric Acid-Water System, J. Chem. Phys., 35, 795-799, 1961.

Erupe, M. E., Viggiano, A. A., and Lee, S.-H.: The effect of trimethylamine on atmospheric nucleation involving $\mathrm{H}_{2} \mathrm{SO}_{4}$, Atmos. Chem. Phys., 11, 4767-4775, doi:10.5194/acp-11-47672011, 2011.

Fuchs, N. A.: On the stationary charge distribution on aerosol particles in a bipolar ionic atmosphere, Geofis. Pura. Appl., 56, 185193, 1963.

Ge, X., Wexler, A. S., and Clegg, S. L.: Atmospheric amines - Part I. A review, Atmos. Environ., 45, 524-546, 2011.

Hanson, D.: Mass accommodation of $\mathrm{H}_{2} \mathrm{SO}_{4}$ and $\mathrm{CH}_{3} \mathrm{SO}_{3} \mathrm{H}$ on water-sulfuric acid solutions from 6 to $97 \%$ RH, J. Phys. Chem. A., 109, 6919-6927, doi:10.1021/jp0510443, 2005.

Hanson, D. R. and Eisele, F. L.: Diffusion of $\mathrm{H}_{2} \mathrm{SO}_{4}$ in humidified nitrogen: Hydrated $\mathrm{H}_{2} \mathrm{SO}_{4}$, J. Phys. Chem. A, 104, 1715-1719, 
2000.

Hanson, D. R. and Eisele, F. L.: Measurement of prenucleation molecular clusters in the $\mathrm{NH}_{3}, \mathrm{H}_{2} \mathrm{SO}_{4}, \mathrm{H}_{2} \mathrm{O}$ system, J. Geophys. Res., 107, doi:10.1029/2001JD001100, 2002.

Hanson, D. R. and Kosciuch, E.: The $\mathrm{NH}_{3}$ mass accommodation coefficient for uptake onto sulfuric acid solutions, J. Phys. Chem. A, 107, 2199-2208, 2003.

Hanson, D. R. and Lovejoy, E. R.: Measurement of the thermodynamics of the hydrated dimer and trimer of sulfuric acid, J. Phys. Chem. A, 110, 9525-9528, doi:10.1021/jp062844w, 2006.

Hanson, D. R., Eisele, F. L., Ball, S. M., and McMurry, P. M.: Sizing small sulfuric acid particles with an ultrafine particle condensation nucleus counter, Aerosol Sci. Tech., 36, 554-559, 2002.

Hanson, D. R, McMurry, P. H., Jiang, J., Tanner, D., and Huey, L. G.: Ambient Pressure Proton Transfer Mass Spectrometry: Detection of Amines and Ammonia, Environ. Sci. Technol., 45, 8881-8888, doi:10.1021/es201819a, 2011.

Hermann, E., Brus, D., Hyvärinen, A.-P., Stratmann, F., Wilck, M., Lihavainen, H., and Kulmala, M.: A Computational Fluid Dynamics Approach to Nucleation in the Water-Sulfuric Acid System, J. Phys. Chem. A, 114, 8033-8042, 2010.

IPCC: Fourth Assessment Report, Climate Change 2007: Working Group I: The Physical Science Basis, Technical Summary 2.2, Cambridge University Press, New York, USA available at: http://www.ipcc.ch/publications_and_data/ar4/wg1/en/ tssts-2-2.html, 2007.

Kirkby, J., Curtius, J., Almeida, J., Dunne, E., Duplissy, J., Ehrhart, S., Franchin, A., Gagne, S., Ickes, L., Kurten, A., Kupc, A., Metzger, A., Riccobono, F., Rondo, L., Schobesberger, S., Tsagkogeorgas, G., Wimmer, D., Amorim, A., Bianchi, F., Breitenlechner, M., David, A., Dommen, J., Downard, A., Ehn, M., Flagan, R. C., Haider, S., Hansel, A., Hauser, D., Jud, W., Junninen, H., Kreissl, F., Kvashin, A., Laaksonen, A., Lehtipalo, K., Lima, J., Lovejoy, E. R., Makhmutov, V., Mathot, S., Mikkila, J., Minginette, P., Mogo, S., Nieminen, T., Onnela, A., Pereira, P., Petaja, T., Schnitzhofer, R., Seinfeld, J. H., Sipila, M., Stozhkov, Y., Stratmann, F., Tome, A., Vanhanen, J., Viisanen, Y., Vrtala, A., Wagner, P. E., Walther, H., Weingartner, E., Wex, H., Winkler, P. M., Carslaw, K. S., Worsnop, D. R., Baltensperger, U., and Kulmala, M.: Role of sulphuric acid, ammonia and galactic cosmic rays in atmospheric aerosol nucleation, Nature, 476, 429, doi:10.1038/nature10343, 2011.

Kuang, C.: Atmospheric nucleation: Measurements, mechanisms, and dynamics, in Department of Chemical Engineering and Materials Science, University of Minnesota, Minneapolis, 2009.

Kuang, C., Chen, M., McMurry, P. H., and Wang, J.: Optimization of laminar flow ultrafine condensation particle counters for the enhanced detection of $1 \mathrm{~nm}$ condensation nuclei, Aerosol Sci. Technol., 46, 309-315, doi:10.1080/02786826.2011.626815, 2012.

Kulmala, M., Vehkamäki, H., Petaja, T., Dal Maso, M., Lauri, A., Kerminen, V. M., Birmili, W., and McMurry, P. H.: Formation and growth rates of ultrafine atmospheric particles: a review of observations, J. Aerosol Sci., 35, 143-176, 2004.

Kurtén, T., Loukonen, V., Vehkamäki, H., and Kulmala, M.: Amines are likely to enhance neutral and ion-induced sulfuric acid-water nucleation in the atmosphere more effectively than ammonia, Atmos. Chem. Phys., 8, 4095-4103, doi:10.5194/acp-8-4095-2008, 2008.
Laaksonen, A., Talanquer, V., and Oxtoby, D.: Nucleation: Theory and atmospheric applications, Annu. Rev. Phys. Chem., 46, 489524, 1995.

McGraw, R. and Wu, D. T.: Kinetic extensions of the nucleation theorem, J. Chem. Phys., 118, 9337-9347, 2003.

McMurry, P. H., Woo, K. S., Weber, R., Chen, D. R., and Pui, D. Y. H.: Size distributions of 3-10 nm atmospheric particles: implications for nucleation mechanisms, Phil. Trans. R. Soc. Lond. A, 358, 2625-2642, 2000.

Metzger, A., Verheggen, B., Dommen, J., Duplissy, J., Prevot, A. S. H., Weingartner, E., Riipinen, I., Kulmala, M., Spracklen, D. V., Carslaw, K. S., and Baltensperger, U.: Evidence for the role of organics in aerosol particle formation under atmospheric conditions, P. Natl. Acad. Sci., 107, 6646-6651, 2010.

Mirabel, P. and Ponche, J. L.: Studies of gas-phase clustering of water on sulphuric acid molecules, Chem. Phys. Lett., 183, $21-$ 24, 1991.

Nel, A.: Air Pollution-Related Illness: Effects of Particles Science, Science, 308, 804-806, 2005.

Noppel, M.: Ethnalpy and entropy changes in formation of gasphase sulfuric acid hydrates and dehydrates as a result of fitting to experimental pressure data, J. Geophys. Res., 105, 19779-19785, 2000.

Nowak, J. B., Huey, L. G., Russell, A. G., Tian, D., Neuman, J. A., Orsini, D., Sjostedt, S. J., Sullivan, A. P., Tanner, D. J., Weber, R. J., Nenes, A., Edgerton, E., and Fehsenfeld, F. C.: Analysis of urban gas phase ammonia measurements from the 2002 Atlanta Aerosol Nucleation and Real-Time Characterization Experiment (ANARChE), J. Geophys. Res, 111, D17308, doi:10.1029/2006JD007113, 2006.

Oberdorster, G., Ferin, J., Gelein, R., Soderholm, S. C., and Finkelstein, J.: Role of the alveolar macrophage in lung injury-Studies with ultrafine particles, Environ. Health Perspect., 97, 193-199, 1992.

O'Dowd, C. D., Aalto, P. P., Yoon, Y. J., and Hamerib, K.: The use of the pulse height analyser ultrafine condensation particle counter (PHA-UCPC) technique applied to sizing of nucleation mode particles of differing chemical composition, J. Aerosol Sci., 35, 205-216, 2004.

Oxtoby, D. W. and Kashchiev, D.: A general relation between the nucleation work and the size of the nucleus in multicomponent nucleation, J. Chem. Phys., 100, 7665-7671, 1994.

Panta, B., Glasoe, W. A., Zollner, J. A., Carlson, K. K., and Hanson, D. R.: Computational Fluid Dynamics of a Cylindrical Nucleation Flow Reactor with Detailed Cluster Thermodynamics, submitted to J. Phys. Chem. A, 2012.

Reiss, H.: The Kinetics of Phase Transitions in Binary Systems, J. Chem. Phys., 18, 840-848, 1950.

Saros, M. T., Weber, R. J., Marti, J. J., and McMurry, P. H.: Ultrafine aerosol measurement using a condensation nucleus counter with pulse height analysis, Aerosol Sci. Tech., 25, 200-213, 1996.

Sipilä, M., Berndt, T., Petäjä, T., Brus, D., Vanhanen, J., Stratmann, F., Patokoski, J., Mauldin III, R. L., Hyvärinen, A. P., Lihavainen, H., and Kulmala, M.: The role of sulfuric acid in atmospheric nucleation, Science, 327, 1243-1246, doi:10.1126/science.1180315, 2010.

Stoltzenburg, M. R. and McMurry, P. H.: An ultrafine aerosol condensation nucleus counter, Aerosol Sci. Technol., 14, 48-65, 1991. 
Vehkamäki, H., Kulmala, M., Napari, I., Lehtinen, K. E. J., Timmreck, C., Noppel, M., and Laaksonen A.: An improved parameterization for sulfuric acid-water nucleation rates for tropospheric and stratospheric conditions, J. Geophys. Res., 107, 4622, doi:10.1029/2002JD002184, 2002.

Viisanen, Y., Kulmala, M., and Laaksonen, A.: Experiments on gas liquid nucleation of sulphuric acid and water, J. Chem. Phys., 107, 920-926, 1997.

Weber, R. J., McMurry, P. H., Mauldin, L., Tanner, D. J., Eisele, F. L., Brechtel, F. J., Kreidenweis, S. M., Kok, G. L., Schillawski, R. D., and Baumgardner, D.: A study of new particle formation and growth involving biogenic trace gas species measured during ace-1, J. Geophys. Res., 103, 16385-16396, 1998.

Weber, R. J., McMurry, P. H., Mauldin, R. L., Tanner, D. J., Eisele, F. L., Clarke, A. D., and Kapustin, V. N.: New particle formation in the remote troposphere: A comparison of observations at various sites, Geophys. Res. Lett., 26, 307-310, 1999.
Wyslouzil, B. E., Seinfeld, J. H., Flagan, R. C., and Okiuyama, K.: Binary nucleation in acid-water systems ii. Sulfuric acid-water and a comparison with methanesulfonic acid-water, J. Chem. Phys., 94, 6842-6850, 1991.

Yu, H., McGraw, R., and Lee, S. H.: Effects of amines on formation of sub-3 nm particles and their subsequent growth, Geophys. Res. Lett., 39, L02807, doi:10.1029/2011GL050099, 2012.

Young, L. H., Benson, D. R., Kameel, F. R., Pierce, J. R., Junninen, H., Kulmala, M., and Lee, S.-H.: Laboratory studies of $\mathrm{H}_{2} \mathrm{SO}_{4} / \mathrm{H}_{2} \mathrm{O}$ binary homogeneous nucleation from the $\mathrm{SO}_{2}+\mathrm{OH}$ reaction: evaluation of the experimental setup and preliminary results, Atmos. Chem. Phys., 8, 4997-5016, doi:10.5194/acp-84997-2008, 2008.

Zhang, R. H., Suh, I., Zhao, J., Zhang, D., Fortner, E. C., Tie, X., Molina, L. T., and Molina, M. J.: Atmospheric new particle formation enhanced by organic acids, Science, 304, 1487-1490, 2004. 